\title{
APLICAÇÕES SINTÉTICAS DO ÁCIDO MUCOBRÔMICO E DA 3,4-DIBROMOFURAN-2(5H)-ONA
}

\section{Silvio Cunha* e Caio C. Oliveira}

Instituto de Química, Universidade Federal da Bahia, Campus de Ondina, 40170-290 Salvador - BA / Instituto Nacional de Ciência e Tecnologia em Energia e Ambiente, Universidade Federal da Bahia, Campus de Ondina, 40170-290 Salvador - BA, Brasil

Recebido em 23/11/10; aceito em 1/4/11; publicado na web em 10/6/11

\begin{abstract}
SYNTHETIC APPLICATIONS OF MUCOBROMIC ACID AND 3,4-DIBROMOFURAN-2(5H)-ONE. This review describes the use of two biomass-derivate butenolides as intermediates in organic synthesis, mucobromic acid and its reduced derivative 3,4-dibromofuran-2(5H)-one. The ambiphilic and ambident character of such butenolides make them versatile starting materials in the synthesis of natural and/or bioactive compounds. Thus, the reactions of mucobromic acid with C-nucleophiles and heteronucleophiles are described, as well as the nucleophilic addition to carbonyl reactions of 3,4-dibromofuran-2(5H)-one. Besides, both compounds are active in diverse metal cross-coupling reactions, manly with palladium in Suzuki and Sonogashira reactions.
\end{abstract}

Keywords: mucobromic acid; 3,4-dibromofuran-2(5H)-one; butenolides.

\section{INTRODUÇÃO}

A ciência Síntese Orgânica passa por um momento de revitalização que inclui, entre outros aspectos, a preocupação com a eficiência da metodologia sintética e sua aplicação numa síntese total, quer seja um produto natural ou uma substância valorada por suas propriedades biológicas ou físico-químicas. ${ }^{1-3} \mathrm{~A}$ incorporação de materiais de partida obtidos de fontes renováveis, a preocupação com o menor consumo de energia, o emprego de métodos e técnicas para acelerar e/ou promover reações antigas e novas passaram a ser metas do planejamento sintético. ${ }^{4,5}$ Estas modificações podem ser relacionadas com incrementos no design experimental. Desta forma, Carlson propôs o conceito da reação ideal, que deve ser realizada em água, o material de partida de fácil acesso, barato, não tóxico e o produto facilmente isolado em rendimento quantitativo. ${ }^{6}$ Complementarmente, Wender preconizou que a economia de etapas é o fator de maior influência na viabilidade de uma síntese, pois determina tempo, custo, geração de resíduos e escala do processo. ${ }^{7}$ Portanto, novas reações devem ser desenvolvidas para que os princípios da Química Verde sejam atendidos. ${ }^{8}$ Estas condições de idealidade para uma síntese norteiam os desafios a serem perseguidos pela comunidade sintética no século atual.

Uma das formas de se obter, em poucas etapas, um aumento significativo de complexidade estrutural consiste em empregar moléculas polifuncionalizadas ambifílicas e polidentadas de fácil acesso, que possam, assim, atuar como eletrófilos e/ou nucleófilos. Dentre as que apresentam todas estas características, merecem destaque as furanonas halogenadas como o ácido mucobrômico (1) e o seu derivado reduzido, a 3,4-dibromofuran-2(5H)-ona (2) (Figura 1).

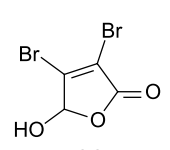

(1)

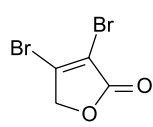

(2)
Figura 1. Ácido mucobrômico 1 e o derivado 3,4-dibromofuran-2(5H)-ona 2

\footnotetext{
*e-mail: silviodc@ufba.br
}

O butenolídeo 9 1 é um excelente material de partida para sínteses orgânicas pois, além de ser densamente funcionalizado, está disponível comercialmente ou é preparado em uma etapa e em alto rendimento, através da bromação do furfural (3, oriundo de biomassa) empregando-se água como solvente (Esquema 1). ${ }^{10}$ Por sua vez, a furanona 2 é facilmente obtida a partir da redução de $\mathbf{1}$ com $\mathrm{NaBH}_{4}$, em escala multigrama (Esquema 2). ${ }^{11}$

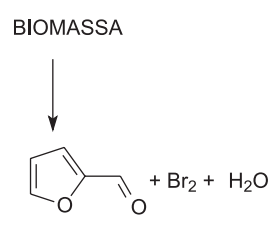

(3)

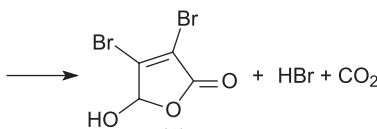

(1)
Esquema 1. Síntese do ácido mucobrômico 1

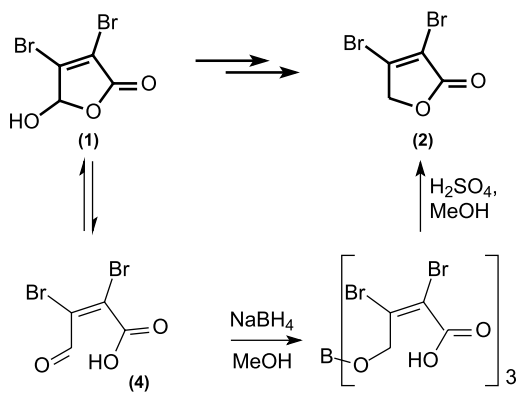

Esquema 2. Síntese da 3,4-dibromofuran-2(5H)-ona 2

O interesse em estudar a reatividade de $\mathbf{1}$ e $\mathbf{2}$ é decorrente do grande número de produtos naturais e moléculas de interesse biológico que apresentam o núcleo de butenolídeos polissubstituídos em suas estruturas (Figura 2). ${ }^{12}$ Assim, o objetivo desta revisão é apresentar as aplicações sintéticas dos butenolídeos $\mathbf{1}$ e $\mathbf{2}$ nos últimos 10 anos, bem como as suas aplicações em síntese total. Adicionalmente, os aspectos mecanísticos das reações são tratados de forma unificada, sistematizando-os. 


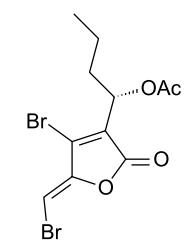

acetoxifrimbolídeo bactericida<smiles>CC(C)C1=C(Cc2ccccc2)C(=O)O/C1=C\c1cc(Cl)c(O)c(Cl)c1</smiles>

(5c)

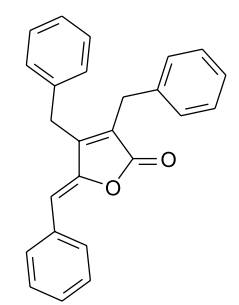

maculalactona B anti-incrustante para navios (5b)

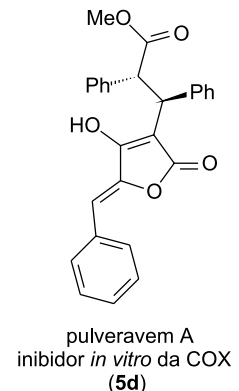

(5d)
Figura 2. Exemplos de butenolídeos polissubstituídos de ocorrência natural ${ }^{12}$

\section{APLICAÇÕES SINTÉTICAS DO ÁCIDO MUCOBRÔMICO}

O ácido mucobrômico (1) é um oxo-ácido que existe em equilíbrio entre as formas cíclica e acíclica. Os dados de infravermelho indicam que a primeira é predominante tanto no estado sólido quanto em solução, ${ }^{13}$ no entanto, o padrão de reatividade de 1 é melhor explicitado na sua forma acíclica (Esquema 3).

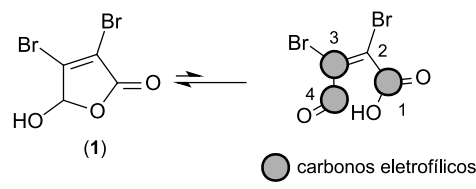

Esquema 3. Equilíbrio e padrão de reatividade de 1

\section{Reações do ácido mucobrômico com nucleófilos de carbono}

As duas carbonilas de $\mathbf{1}$ são bons centros eletrofílicos, pois estão conjugadas a grupos retiradores de elétrons. Adicionalmente, a ligação a um átomo de bromo torna $\mathrm{C} 3$ um poderoso aceptor de Michael. Assim, a presença destes centros eletrofílicos faz de $\mathbf{1}$ um sinton para formação de butenolídeos C-substituídos via reação com nucleófilos de carbono.

Em 2003, Zhang e colaboradores descreveram a formação de $\gamma$-alil- $\gamma$-butirolactonas a partir da reação de Barbier em $\mathrm{THF} / \mathrm{H}_{2} \mathrm{O}$ entre 1 e brometos de alila primários com diferentes substituintes no
Tabela 1. Alilação do ácido mucobrômico (1) promovida por metal<smiles>O=C1OC(O)C(Br)=C1Br</smiles>

Entrada Brometo de alila

grupo vinila (6a-d). A reação foi promovida por In ou Sn em excesso de $20 \%$ e $\mathrm{NH}_{4} \mathrm{Cl}$ catalítico (Tabela 1$){ }^{14}$

Os rendimentos da reação de alilação variaram entre 41 e $75 \%$ e com excelentes quimio- e regiosseletividade. No entanto, não é possível afirmar qual metal é o melhor promotor, pois a reação que não ocorreu na presença de estanho (entrada 3), não foi realizada com índio.

A reação homo-aldólica de Mukayama entre 1 e silil ceteno acetais $(\mathbf{8} \mathbf{a}$ e 8b) e silil enol éter (8c) na presença de um ácido de Lewis representa um avanço na síntese de $\gamma$-butirolactonas- $\gamma$-substituídas (Esquema 4). ${ }^{15} \mathrm{O}$ butenolídeo 1 é instável em meio básico, assim, a tentativa de realizar a reação aldólica nas condições clássicas, teoricamente, não é viável.

As reações aldólicas foram realizadas a baixas temperaturas, em $\mathrm{MeNO}_{2}$, utilizando 0,1 equivalentes do catalisador, sendo o $\mathrm{ZnCl}_{2}$ eficiente para a reação de $\mathbf{1}$ com $\mathbf{8 a}$ e $\mathbf{8 b}$, promovendo a formação de $\mathbf{9 a}$ e $\mathbf{9 b}$ em 48 e $75 \%$ de rendimento, respectivamente. Empregando o SEE $\mathbf{8 c}$, um nucleófilo mais poderoso que $\mathbf{8 a}$ e $\mathbf{8 b}$, e um ácido de Lewis mais duro, o $\mathrm{Sc}(\mathrm{OTf})_{3}$, foi possível a formação da butirolactona $9 \mathrm{c}$.

$\mathrm{O}$ ataque nucleofílico de $\mathbf{8 a}$ com $\mathbf{1}$ pode ocorrer via estados de transição diastereoméricos 10a e 10b. A proximidade entre o hidrogênio da posição 4 do furano e o bromo de $\mathbf{1}$ desfavorece a formação de $\mathbf{1 0 b}$ (Esquema 5).

A adição nucleofílica de um grupo metileno ativado a um aldeído ou cetona seguida de eliminação de uma molécula de água é conhe-
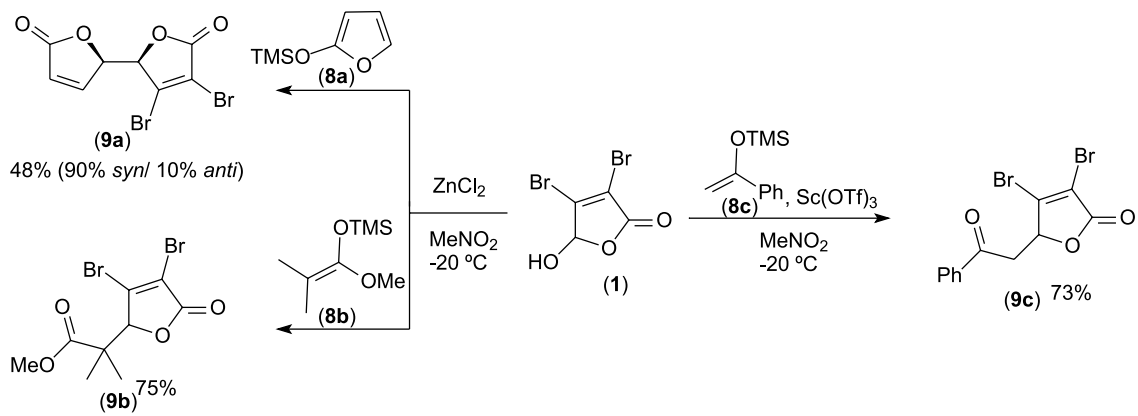

(9c) $73 \%$ 


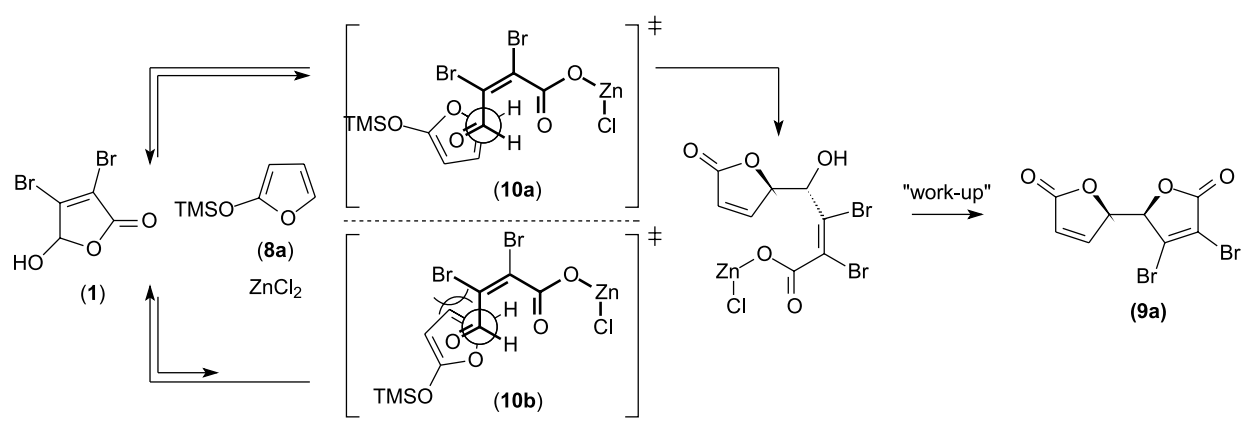

Esquema 5. Origem da diastereosseletividade na formação de $\mathbf{9}^{a}$

cida como reação de Knoevenagel.${ }^{16}$ No método clássico, esta reação é realizada em meio básico, o que é uma limitação para substratos instáveis nestas condições. Baseado nisto, Zhang estudou a reação de condensação entre $\mathbf{1}$ e malonato de dietila (11a) na presença de ácidos de Lewis. ${ }^{17}$ Os melhores resultados foram obtidos quando a reação foi processada com $\mathrm{ZnCl}_{2}$ ou $\mathrm{In}(\mathrm{OAc})_{3}$ em tolueno, com remoção azeotrópica de água.

Esta reação de adição tipo Knoevenagel ocorre em duas etapas, adição nucleofílica do enolato do $\beta$-dicarbonílico ao ácido mucobrômico (1), seguida de lactonização do intermediário $\mathbf{1 2 b}$. O rendimento da reação é melhorado quando é retirada a água formada no meio reacional (Esquema 6).

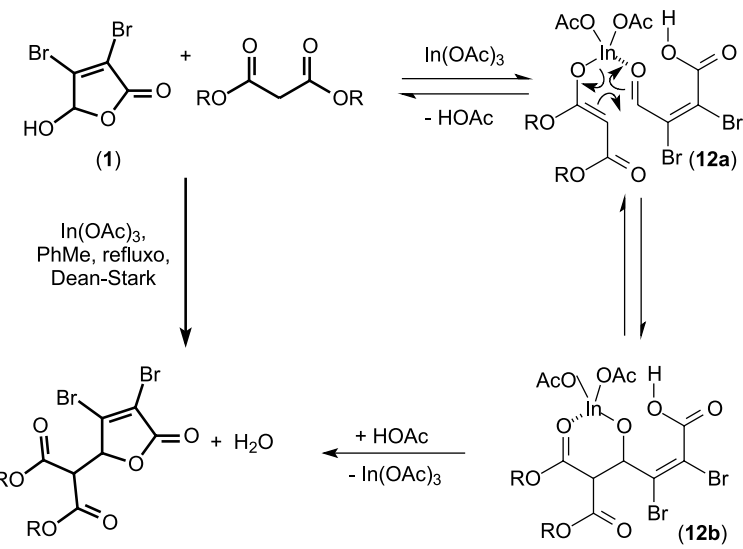

Esquema 6. Proposta mecanística para a reação tipo Knoevenagel entre 1 e $\beta$-dicarbonílicos

A reação catalisada por $\mathrm{ZnCl}_{2}$ apresentou bons rendimentos com diversos $\beta$-dicarbonílicos. Contudo, o $\operatorname{In}(\mathrm{OAc})_{3}$ foi escolhido como melhor catalisador por promover a formação dos produtos em maior rendimento, menor tempo e maior turnover que o $\mathrm{ZnCl}_{2}$ (Tabela 2), mas não houve a formação do produto de Knoevenagel com acetilacetona e acetoacetato de etila.

Os compostos 13a e 13b provaram ser intermediários versáteis para a síntese de $\gamma$-alquilidenobutenolídeos, pois, na presença de DABCO em solventes apróticos, levaram à formação de 14a e 14b (Esquema 7). ${ }^{18}$

A proposta mecanística para a formação dos alquilidenos $\mathbf{1 4 a - b}$ pode ser racionalizada em três etapas, envolvendo a enolização da lactona mediada por DABCO seguida de reação ácido-base do enol $\mathbf{1 5} \mathbf{a}$ com o sal de amônio, formando a lactona $\alpha, \beta, \gamma, \delta$ insaturada $\mathbf{1 5 b}$ que, por fim, sofre eliminação 1,4 mediada por DABCO, liberando $\mathrm{HBr}$ (Esquema 8).

Em mais um estudo sobre a reatividade do ácido mucobrômico (1) frente a C-nucleófilos, Zhang e colaboradores sintetizaram $\gamma$-aril- $\gamma$-butirolactonas via acilação de Friedel-Crafts catalisada por In(OTf $)_{3}$. A reação ocorreu apenas com anéis aromáticos substituídos
Tabela 2. Reação de Knoevenagel entre 1 e $\beta$-dicarbonílicos

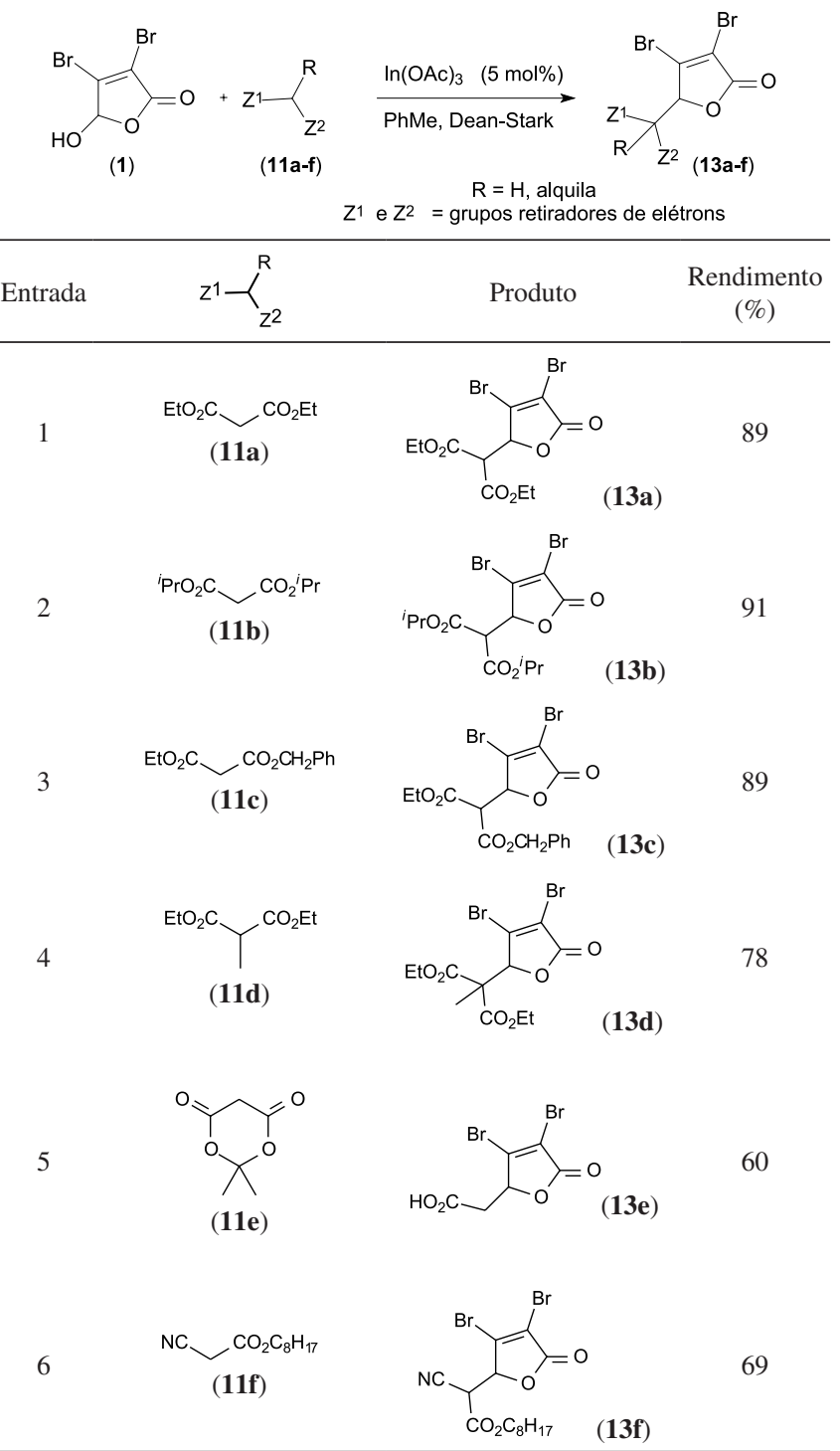

por grupos doadores de elétrons, e foi seletiva para a posição orto em relação às metoxilas (16a-c) (Esquema 9). ${ }^{19}$

A substituição eletrofílica aromática de 1 com o 1,2,4-trimetoxibenzeno ocorre regiosseletivamente em $\mathrm{C} 5$, apesar de $\mathrm{C} 3$ também estar ativado pelo efeito doador de elétrons de duas metoxilas (Esquema 10). Isto pode ser justificado através da repulsão existente entre a metoxila em $\mathrm{C} 4$ do anel e o átomo de bromo presente em C3 de 2, que leva a um estado de transição $\mathbf{1 7 b}$ com maior conteúdo energético que 17a. 
<smiles>[R]OC(=O)C(C([R])[R])C1OC(=O)C(Br)=C1Br</smiles>

$(13 a-b)$<smiles></smiles>

(14a)<smiles>[R]OC(C([R20])=O)=C1OC(=O)C=C1Br</smiles>

$(14 a-b)$<smiles>COC(=O)C(C(=O)O[In])=C1OC(=O)C=C1Br</smiles>

(14b)
Esquema 7. Formação de $\gamma$-alquilidenobutenolídeos promovido por DABCO<smiles>[R]OC(C(=O)O[Na])C1OC(=O)C(Br)=C1Br</smiles><smiles>C1=CN2CCN(CC1)C2</smiles>
$\mathrm{RO}_{2}$

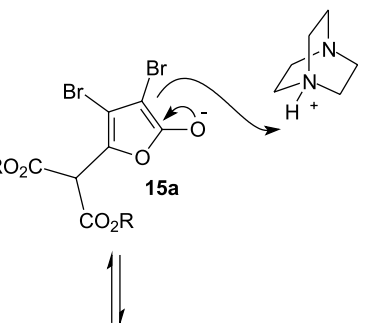<smiles>[R]OC(=O)C([R20])=C1OC(=O)C=C1Br</smiles>

$14 a-b$

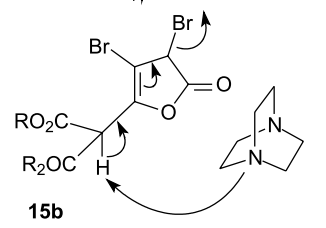

Esquema 8. Proposta mecanística para a formação de $\mathbf{1 2 a}$ e $\mathbf{1 2 b}$

Durante o estudo visando a síntese biomimética do phomoidrido B (18), metabólito do fungo ATCC 74256, Sulikowski empregou a adição nucleofílica do carbânion 20 ao derivado 19 do ácido mucobrômico (Esquema 11). ${ }^{20}$ Após a adição de Michael, a acidificação do meio levou à remoção dos grupos tert-butila e simultânea decarboxilação. O monoácido resultante foi reduzido para gerar o intermediário<smiles>[R]c1ccc([C@H]2OC(=O)C(Br)=C2Br)cc1</smiles><smiles>COc1cc(OC)c(C2OC(=O)C(Br)=C2Br)c(OC)c1</smiles>

$(16 a)$
$82 \%$<smiles>COc1ccc(C2OC(=O)C(Br)=C2Br)c(OC)c1OC</smiles><smiles>COc1cc(OC)c(C2OC(=O)C(Br)=C2Br)cc1OC</smiles>

$(16 c)$
$45 \%$

Esquema 9. Acilação de Friedel-Crafts de 1 catalisada por In(OTf)

21 em rendimentos que variaram entre $31-49 \%$, para as três etapas.

\section{Reação do ácido mucobrômico com heteronucleófilos}

A versatilidade sintética de $\mathbf{1}$ é muito ampla em função deste eletrófilo poder reagir tanto com C-nucleófilos quanto com heteronucleófilos. A possibilidade de funcionalizar todos os carbonos de 2 foi utilizada por Kerdesky e colaboradores na síntese, em escala multiquilograma, do ABT-963 (22), um inibidor seletivo da COX$2 .{ }^{21}$ Os inibidores seletivos da COX-2 são alvos de interesse para a indústria farmacêutica, pois, diferentemente dos anti-inflamatórios não esteroidais, não provocam efeitos colaterais ao trato gastrointestinal. ${ }^{22}$

A piridazinona $\mathbf{2 3}$ foi sintetizada em meio aquoso a partir da reação da hidrazina (24) com 1 (Esquema 12). Em seguida, o bromo original da posição 3 de $\mathbf{1}$ foi seletivamente substituído pelo alcóxido primário de 25, em $78 \%$ de rendimento. Uma reação de Suzuki com o ácido borônico 26 e posterior oxidação do tio-éter com Oxone ${ }^{\circledR}$ levou à formação de $\mathbf{2 2}$ em $\mathbf{7 4 \%}$ de rendimento. Destaque-se que nesta rota foram obtidos $6,75 \mathrm{~kg}$ do anti-inflamatório.

$\mathrm{Na}$ busca por novos antibióticos, Lattman relatou a síntese de 3-bromo-4-amino-5-hidróxi-2-furanonas baseado na reação de $\mathbf{2}$ com formamidas primárias 27a-c, catalisada por $\mathrm{H}_{2} \mathrm{SO}_{4}$. Foram obtidas três

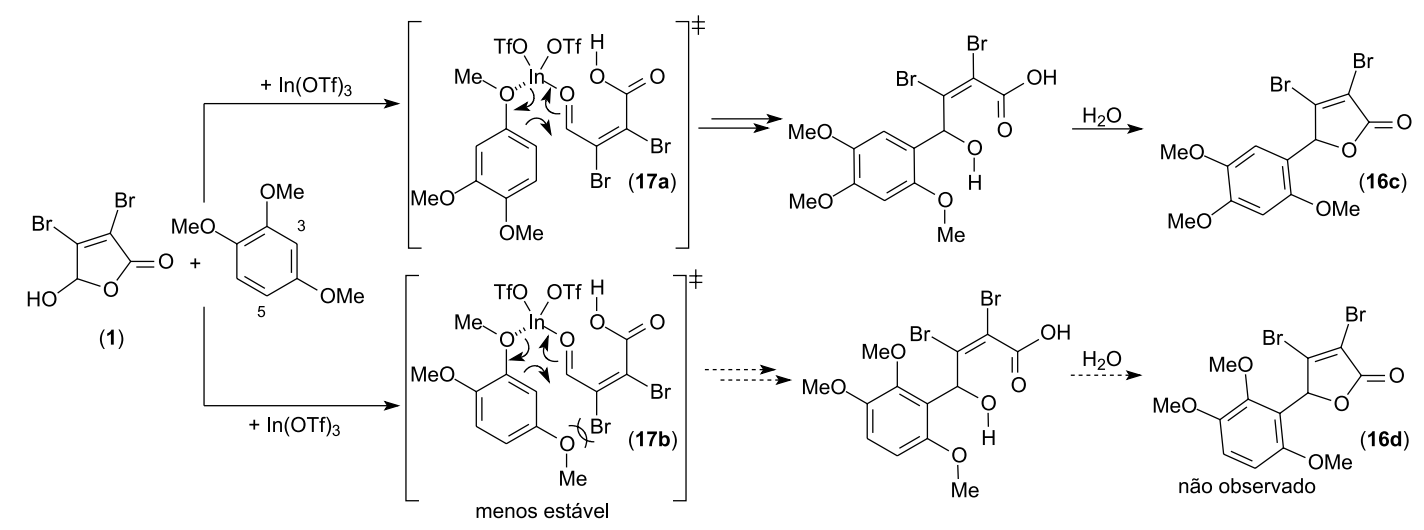

Esquema 10. Regiosseletividade na acilação de Friedel-Crafts

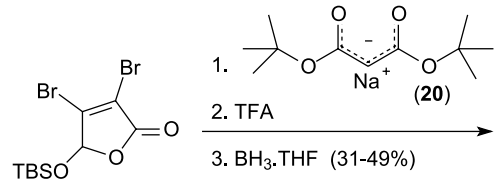

(19)

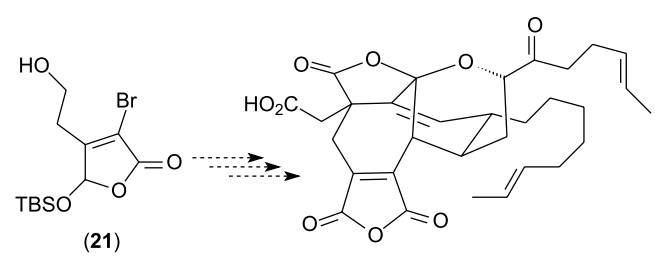

(21) 


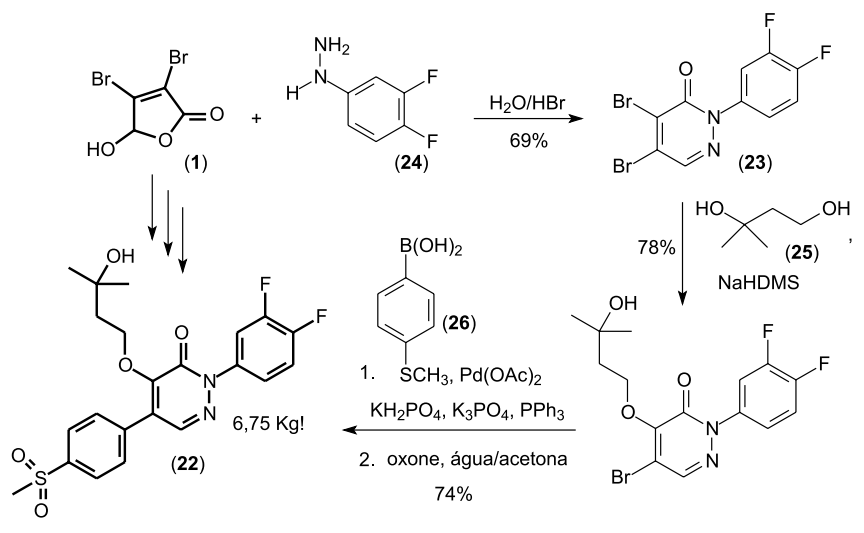

Esquema 12. Síntese do ABT-963

$\alpha$-bromo-enaminonas $\mathbf{2 8 a - c}$, cujos rendimentos não foram descritos (Esquema 13). ${ }^{23}$ Apesar do histórico de enaminonas com atividade antibacteriana, as moléculas 28a-c não apresentaram bioatividade significativa. ${ }^{24}$ Ainda buscando potenciais antimicrobianos, Lattmann reportou a síntese de 3-bromo-4-imidazo-5-metóxi-2-furanonas (29a-d). ${ }^{25}$ A substituição da hidroxila em C4 por uma metoxila torna as $\alpha$-bromo-enaminonas 29a-d mais lipossolúveis que 28a-c.<smiles>O=C1OC(O)C(Br)=C1Br</smiles>

(1)<smiles>CNC1=C(Br)C(=O)OC1O</smiles><smiles>[R]NC=O</smiles><smiles>COCCOCCO</smiles>

$(27 a-c)$<smiles>O=C1OC(O)C(N[N+](=O)[O-])=C1Br</smiles>

Esquema 13. Adição nucleofílica de formamidas a 1

As butirolactonas 29a-d foram sintetizadas em duas etapas, envolvendo a formação do éter metílico do ácido mucobrômico (30) via adição de metanol em meio ácido, seguida de adição nucleofílica de um derivado de imidazol, presente em excesso no meio reacional (Esquema 14). Das butirolactonas, apenas estas quatro (29a-d) demonstraram potencial como possíveis antibacterianos, com concentração inibitória mínima (MIC) entre 2-16 $\mu \mathrm{g} / \mathrm{g}$ para os micro-organismos S. aureus, E. coli e P. aeruginosa (Tabela 3).

A substituição regiosseletiva no $\mathrm{C} 4$ (rota $\mathbf{b}$ ) de derivados de $\mathbf{1}$ foi realizada por Zhang, em 2003. ${ }^{26}$ Esta metodologia representa um avanço significativo na química deste butenolídeo, uma vez que ataques de heteronucleófilos tendem a ocorrer em C3 via mecanismo de adição-eliminação (rota a) (Esquema 15).

Inicialmente, a diferenciação entre a substituição vinílica, que leva à 30a, e alílica, que gera compostos como 30b, foi avaliada utilizando a reação de Tsuji-Trost. O estudo da eterificação do carbonato 31, derivado do ácido mucoclórico (32), com $m$-cresol (33) apresentou bons resultados quando $\mathrm{Pd}_{2}(\mathrm{dba})_{3}$ foi utilizado como catalisador e CsF como base (Tabela 4). Na ausência da base, não houve formação do produto (entrada 2). A boa surpresa aconteceu quando a reação foi realizada sem o $\mathrm{Pd}_{2}(\mathrm{dba})_{3}$, pois o éter (34) foi obtido em $89 \%$ de rendimento. No entanto, o tempo reacional foi maior (entrada 3 ). Essa metodologia foi expandida para o carbonato bromado 35, que na condição reacional otimizada, produziu $36 \mathrm{em} 91 \%$ de rendimento (Esquema 16).
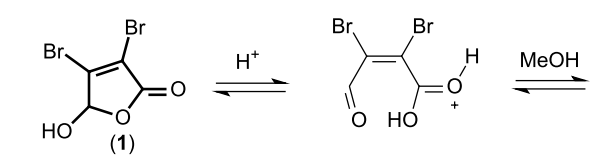<smiles>COC(O)/C(Br)=C(/Br)C(=O)O</smiles><smiles>CO[C@H]1OC(=O)C(Br)=C1n1cncn1</smiles><smiles></smiles><smiles>COC1OC(=O)C(Br)=C1Br</smiles>

(30)

Esquema 14. Síntese de 3-bromo-4-imidazo- $\gamma$-alcoxi- $\gamma$-furanonas

Tabela 3. Atividade antibacteriana das 3-bromo-4-imidazo- $\gamma$-alcoxi- $\gamma$ furanonas 29a-d

Entrada

$(30 a)$

(30b)

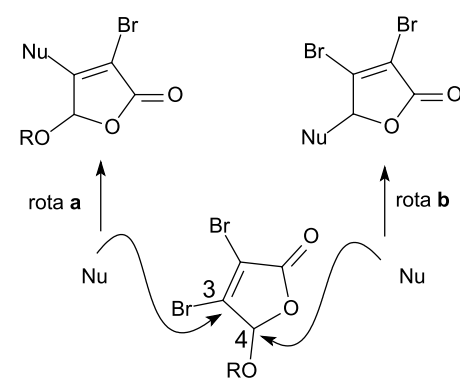

Esquema 15. Regiosseletividade das reações de substituição de 1 com heteronucleófilos

\section{Reações do ácido mucobrômico - acoplamento cruzado mediadas por paládio}

As reações de acoplamento catalisadas por paládio representam uma das mais importantes vias de formação de ligação C-C. ${ }^{27}$ Dentre elas destacam-se as reações de Mizoroki-Heck, Suzuki e Sonogashira. Os mecanismos das reações de Suzuki (Esquema 17) e Sonogashira (Esquema 18) são compostos por três etapas: adição oxidativa do paládio ao haleto vinílico; transmetalação com um organometálico nucleofílico e, eliminação redutiva. A primeira e a última etapas 
Tabela 4. Eterificação do carbonato 31

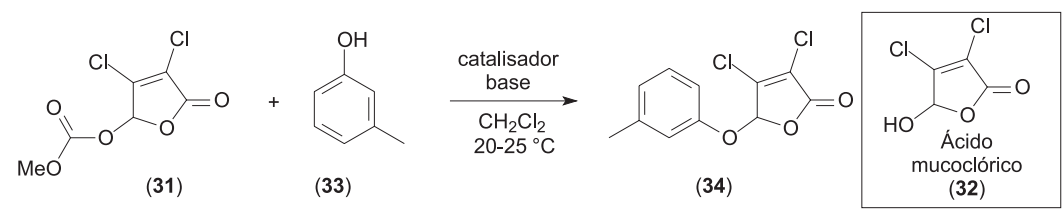

\begin{tabular}{ccccc}
\hline Entrada & Catalisador & Base & Tempo (h) & Rendimento $(\%)$ \\
\hline 1 & $\mathrm{Pd}_{2}(\mathrm{dba})_{3} 3 \%$ & $\mathrm{CsF} 20 \%$ & 4 & 83 \\
2 & $\mathrm{Pd}_{2}(\mathrm{dba})_{3} 3 \%$ & --- & 65 & --- \\
3 & --- & $\mathrm{CsF} 20 \%$ & 7 & 89 \\
\hline
\end{tabular}<smiles>COC(=O)OC1OC(=[OH+])C(Br)=C1Br</smiles>

Esquema 16. Substituição nucleofílica alílica catalisada por CsF

ocorrem da mesma forma nas duas reações. A principal diferença está relacionada com a natureza do nucleófilo durante a transmetalação: um organoboro (37a - Esquema 17) na reação de Suzuki ou um acetilídio de cobre (37b - Esquema 18) na reação de Sonogashira.

Na reação de Suzuki a continuidade do ciclo catalítico depende da substituição do halogênio por uma base (normalmente um fluoreto) na esfera de coordenação do paládio, enquanto que na reação de So-

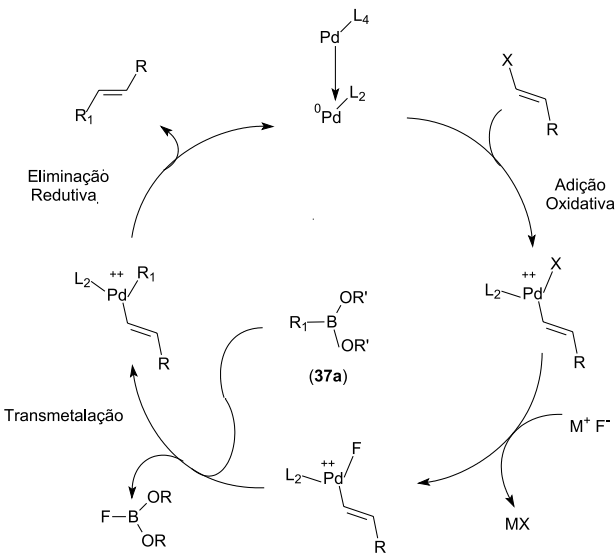

Esquema 17. Mecanismo geral da reação de Suzuki

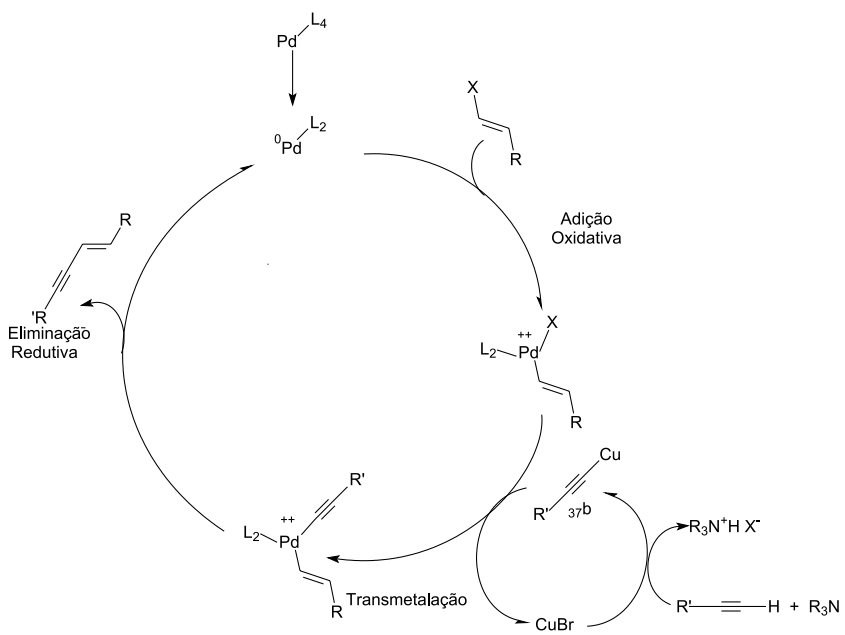

Esquema 18. Mecanismo geral para a reação de Sonogashira nogashira a base é necessária para desprotonar o alcino complexado ao cobre.$^{28}$ Como a presença de uma base é necessária para o sucesso dessas reações, o emprego do ácido mucobrômico como substrato para reações de acoplamento cruzado representa um desafio, principalmente nas reações em que o nucleófilo é uma base forte, uma vez que $\mathbf{1}$ apresenta função ácida e é instável em meio básico. Por este motivo, a maior parte dos relatos das reações de acoplamento cruzado utilizam derivados O-protegidos de $\mathbf{1}$.

A única metodologia de acoplamento cruzado que emprega diretamente o ácido mucobrômico (1) foi descrita por Zhang e colaboradores, em 2002. De forma engenhosa, a diarilação de 1 foi possível ao utilizar excesso do ácido fenil-borônico (38) em um sistema bifásico, o qual evita a decomposição de $\mathbf{1}$, já que o butenolídeo e a base solubilizam em fases distintas (Esquema 19). ${ }^{29}$ Todavia, o rendimento para esta reação não foi informado. No entanto, quando o substrato foi o ácido mucoclórico (31), nas mesmas condições, o produto 39 foi obtido em $71 \%$ de rendimento.

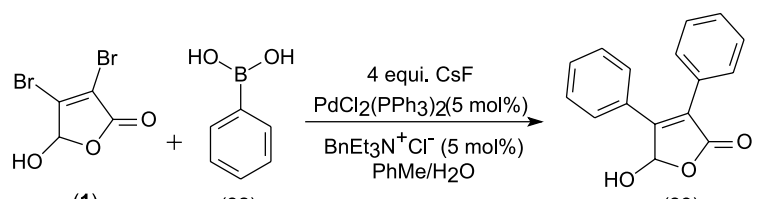

(1)

(38)

(39)

Esquema 19. Diarilação de 2 via reação de Suzuki

Essa metodologia foi utilizada por Krayushkin para sintetizar o anidrido fotocrômico (40). A reação de Suzuki forneceu o intermediário 41 em 32\% de rendimento. A substituição de $\mathrm{PdCl}_{2}\left(\mathrm{PPh}_{3}\right)_{2}$ por $\mathrm{Pd}\left(\mathrm{PPh}_{3}\right)_{4}$ não proporcionou o aumento do rendimento e, em ambos os casos, o produto majoritário foi o bis-tiofeno 42. A síntese foi concluída com a oxidação de $\mathbf{4 1}$ com $\mathrm{KMnO}_{4}$ (Esquema 20). ${ }^{30}$

Em um estudo visando comprovar a rota biossintética para a formação do metabólito de fungo phomoidrido B (18), o anidrido

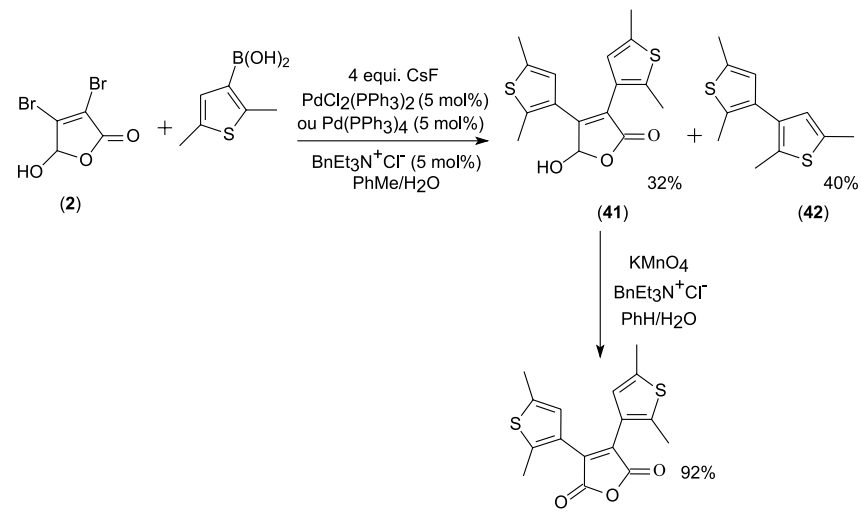

(40)

Esquema 20. Síntese do anidrido fotocrômico 40 
(43) foi obtido em várias etapas. A reação de Suzuki do silil-éter do ácido mucobrômico (19) com o ácido fenil-borônico 44 produziu o butenolídeo deuterado $\mathbf{4 5}$ em $41 \%$ de rendimento. (Esquema 21). ${ }^{31}$

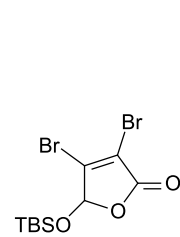

(19)

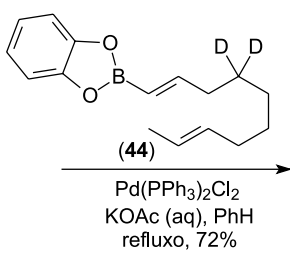
refluxo, $72 \%$

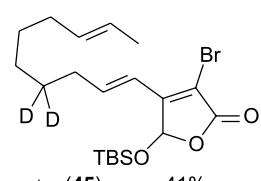

$(45)$

$1 \%$<smiles>[2H]C([2H])(C/C=C/C1=C(CC(=O)SCCNC([2H])([2H])C)C(=O)OC1=O)CCCCCC</smiles>

Esquema 21. Formação do butenolídeo deuterado 42

Após incubação de $\mathbf{4 3}$ e fermentação da cultura do fungo ATCC 74256, o phomoidrido B deuterado (46) foi isolado por HPLC. Este resultado indica que, provavelmente, a biossíntese deste produto natural seja resultado da dimerização decarboxilativa de 43. (Esquema 22).

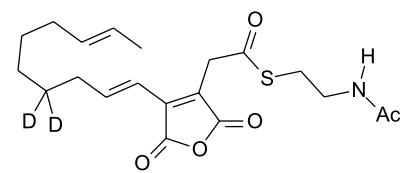

(43)
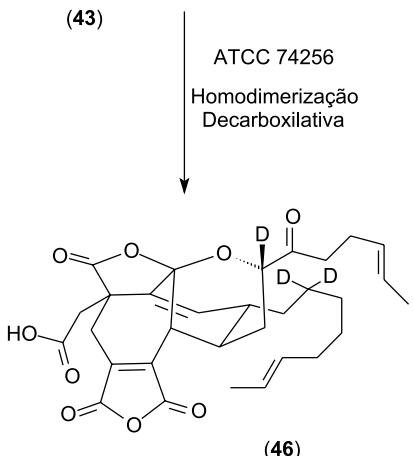

(46)

Esquema 22. Homodimerização decarboxilativa de $\mathbf{4 3}$

Em 2006, Gomez-Paloma e colaboradores reportaram a arilação do derivado de 1 protegido com éter metoxietoximetílico (MEM) 47 via irradiação por micro-ondas (Esquema 23). ${ }^{32}$ Posteriormente, o mesmo grupo publicou um estudo que visava a descoberta de 4-aril$\gamma$-hidróxi- $\gamma$-furanonas (49a-j) com atividade anti-inflamatória. ${ }^{33}$ A síntese destas furanonas foi realizada a partir da arilação de $\mathbf{4 8}$ seguida da desproteção do grupo MEM com o $\mathrm{AlCl}_{3}$ (Esquema 24).<smiles>COC1OC(=O)C(Br)=C1Br</smiles>

(47)

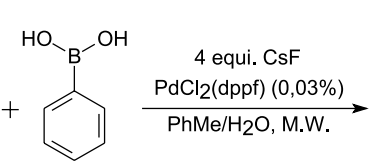

(38)

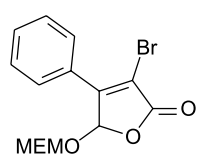

(48) $98 \%$
Esquema 23. Arilação de 42

Os testes in vitro apontaram a furanona 49i como potencial anti-inflamatório dose-dependente, atuando como inibidora da prostaglandina sintetase, com atividade semelhante à dexametasona.
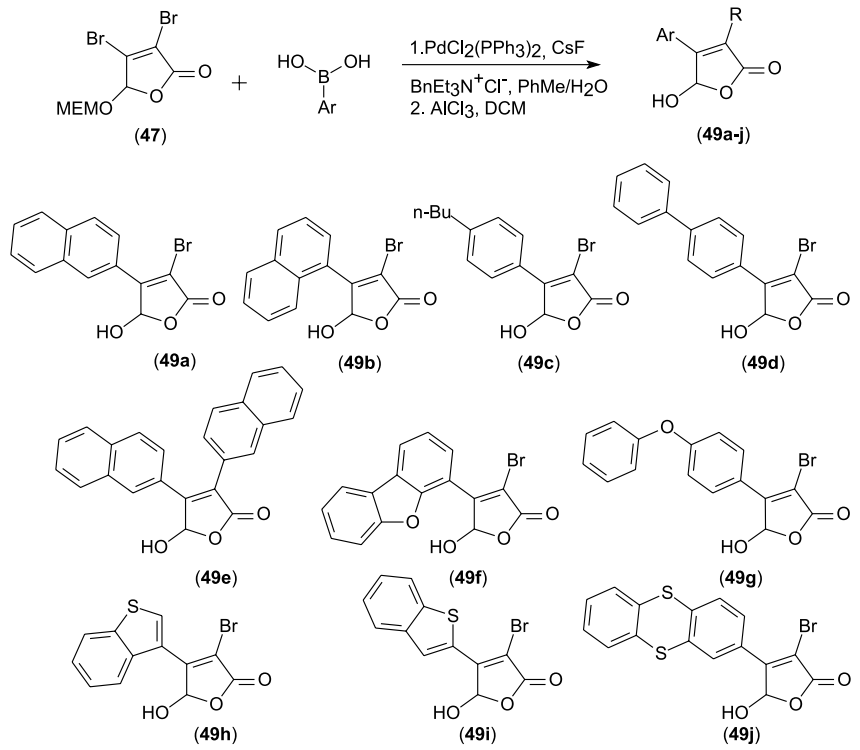

Esquema 24. 4-Aril- $\gamma$-hidróxi- $\gamma$-furanonas

Apesar do grande número de publicações sobre a reação de Mizoroki-Heck, a maioria delas emprega haletos de arila como substrato. ${ }^{34}$ Haletos vinílicos são utilizados em menor frequência como substratos para esta reação. ${ }^{35}$ Supostamente por isto não existem, até o momento, relatos de olefinação para o ácido mucobrômico e seus derivados via reação de Heck.

\section{APLICAÇÕES SINTÉTICAS DA 3,4-DIBROMOFURAN- 2(5H)-ONA}

Duas classes de reações predominam no cenário de transformações envolvendo a furanona $\mathbf{2}$, sua adição nucleofílica a compostos carbonílicos e as reações de acoplamento cruzado mediado por paládio. Assim, a maioria dos estudos explora o caráter nucleofílico da 3,4-dibromofuran-2(5H)-ona, sendo escassos, mas promissores, os estudos onde $\mathbf{2}$ atua como eletrófilo.

\section{Reações da 3,4-dibromofuran-2(5H)-ona - adição nucleofílica à carbonila}

A furanona 2 apresenta reatividade diferenciada do ácido mucobrômico (1) principalmente por C4 possuir caráter nucleofílico em meio básico, uma vez que os hidrogênios ácidos ligados em C4 são facilmente removidos (Figura 3).

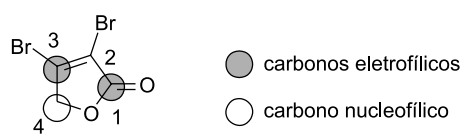

Figura 3. Padrão de reatividade de 2

Em meio básico e na presença de um eletrófilo a furanona 2 pode reagir via ataque nucleofílico do oxigênio (rota a), ou do carbono (rota b), ou ainda pode sofrer decomposição (rota c) (Esquema 25).

Em 2007, Zhang e colaboradores descreveram a reação homoaldol entre a furanona $\mathbf{5 0}$ e diversos aldeídos e cetonas. ${ }^{36}$ As reações foram realizadas em metanol na presença de 0,5 equivalentes de trietilamina (Tabela 5).

Nas reações com aldeídos aromáticos a relação entre os diastereômeros sin/anti foi de 2/1 para a maioria dos produtos (entradas 4-9). Os resultados observados nas reações com 1-naftaldeído e 2-naftalde- 
Tabela 5. Reação homo-aldol entre $\mathbf{4 5}$ e aldeídos aromáticos catalisada por trietilamina

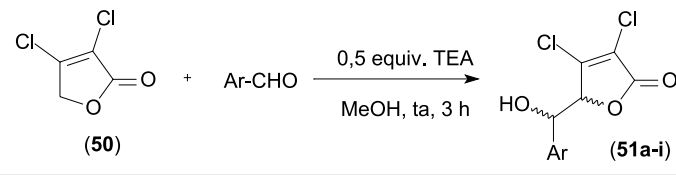

\begin{tabular}{|c|c|c|c|c|c|}
\hline Entrada & Produto & sin/anti rend. $(\%)$ & Entrada & Produto & sin/anti rend. (\%) \\
\hline 1 & & $\begin{array}{l}10 / 1 \\
(66)\end{array}$ & 6 & & $\begin{array}{c}2 / 1 \\
(60)\end{array}$ \\
\hline 2 & & $\begin{array}{c}5 / 1 \\
(64)\end{array}$ & 7 & & $\begin{array}{c}2 / 1 \\
(52)\end{array}$ \\
\hline 3 & & $\begin{array}{c}3 / 1 \\
(50)\end{array}$ & 8 & & $\begin{array}{l}2 / 1 \\
(50)\end{array}$ \\
\hline 4 & & $\begin{array}{c}2 / 1 \\
(79)\end{array}$ & 9 & & $\begin{array}{l}2 / 1 \\
(47)\end{array}$ \\
\hline 5 & & $\begin{array}{c}2 / 1 \\
(68)\end{array}$ & 10 & & $\begin{array}{c}1.4 / 1 \\
(70)\end{array}$ \\
\hline
\end{tabular}

ído indicam que a seletividade é maior para aldeídos orto-substituídos (entradas 3 e 8). Adicionalmente, a presença de grupos retiradores de elétrons na posição orto parece ser o principal fator responsável pela formação preferencial do isômero sin (entradas 1 e 2).<smiles>O=C1OCC(Br)=C1Br</smiles>

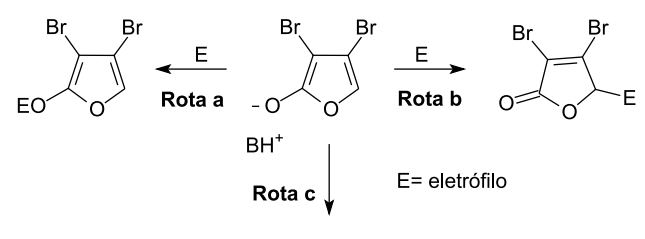

Decomposição

Esquema 25. Nucleofilidade de 2 em meio básico
A racionalização do mecanismo da formação dos butenolídeos 51a-j envolve a enolização de 50, seguida do ataque nucleofílico à carbonila do aldeído. Como o metanol foi utilizado como solvente, a aproximação sinclinal deve ser favorecida uma vez que ocorre maximização do dipolo. ${ }^{37}$ Esta etapa pode ocorrer por dois estados de transição distintos, 52a e 53a. O primeiro, que leva à formação do isômero sin, é favorecido por não apresentar interação gauche entre o anel aromático e o átomo de cloro ligado ao C3 do enolato. A acidificação do meio leva à formação dos adutos de homo-aldol 53a ou 53b (Esquema 26).

Para confirmar a hipótese de que a repulsão estérica entre o anel aromático e o substituinte em C3 do enolato era um dos fatores que contribuía para a diastereosseletividade da reação, foi realizada a reação do benzaldeído (54) com 3,4-dibromofuran-2(5H)-ona (3) (Esquema 27). Nesta reação, a relação sin/anti dos produtos foi 5/1, enquanto que na reação homo-aldol com $\mathbf{5 0}$ foi de 2/1(Tabela 5, entrada 4). O átomo de bromo é mais volumoso do que o de cloro, aumentando assim o caráter repulsivo presente na aproximação representada por 53a (Esquema 26). Desta forma, o caminho reacional que leva à formação do produto sin é favorecido.

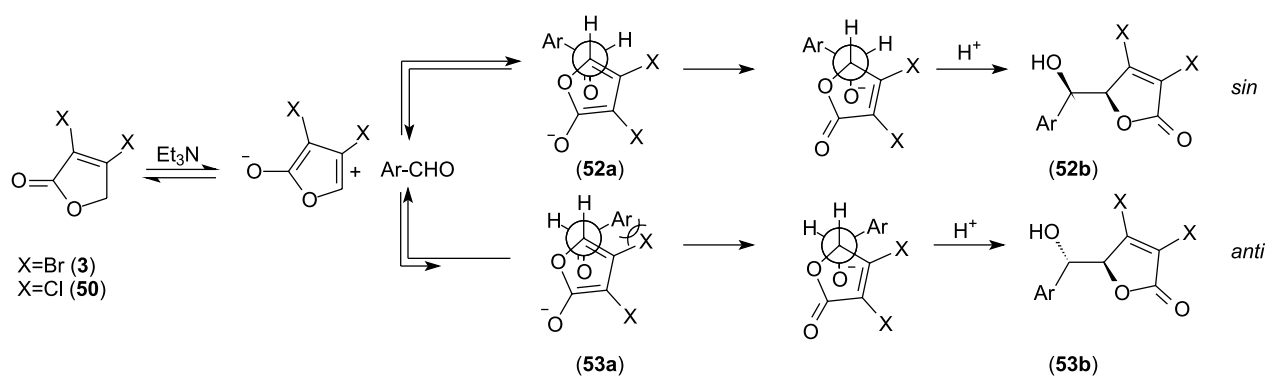

Esquema 26. Proposta mecanística para a homo-aldol 
<smiles>O=C1OCC(Br)=C1Br</smiles>

(3)<smiles>O=Cc1ccccc1-c1ccccc1</smiles>

(54)<smiles>O=C1O[C@H](C(O)c2ccccc2)[C@@H](Br)[C@H]1Br</smiles>

Esquema 27. Reação homo-aldol entre 2 e benzaldeído

O trabalho pioneiro de Zhang em relação à reação homo-aldol em furanonas halogenadas permitiu enxergar $\mathbf{2}$ como um sinton para a formação de $\delta$-hidróxi- $\gamma$-furanonas, que é um núcleo comum em diversos produtos naturais (Figura 4). ${ }^{36}$ Neste cenário, Terada e colaboradores desenvolveram a reação homo-aldol assimétrica catalisada por guanidinas cíclicas quirais $\mathbf{5 6} \mathbf{6}-\mathbf{h}$ (Figura 5). ${ }^{38} \mathrm{~A}$ criação de dois centros adjacentes de configuração definida em uma única etapa, com $100 \%$ de economia atômica, coloca esta reação em destaque na química de 2. Para a seleção do melhor catalisador, avaliou-se a eficiência de formação de $\mathbf{5 1 d}$ a partir da reação de $\mathbf{5 0}$ com benzaldeído (54). A guanidina 56a promoveu a formação do produto em $15 \%$ de rendimento. A inserção de substituinte volumoso no nitrogênio em 56d mostrou ser benéfica para aumentar o rendimento; no entanto, o tempo reacional ainda foi elevado. A guanidina 56e, substituída com anéis deficientes em elétrons, não apresentou atividade catalítica para esta reação. Os melhores resultados, com rendimentos acima de $70 \%$ e tempo reacional abaixo de $8 \mathrm{~h}$ só foram obtidos com $\mathbf{5 6 g}$ e $\mathbf{5 6 h}$, sendo que este último foi escolhido por promover a reação em altos rendimentos e bons excessos diastereo- e enatioméricos (Tabela 6).<smiles>C/C=C/C=C\[C@H](O)C1CCC(=O)O1</smiles>

Figura 4. Exemplos de $\delta$ elou $\gamma$-hidróxi-lactonas em produtos naturais

A adição de acetona como cossolvente aumentou a diastereosseletividade da reação em relação ao uso exclusivo de THF. Nestas condições, foram obtidas $7 \delta$-hidróxi- $\gamma$-furanonas quirais 58a-g derivadas de 2 em rendimentos que variaram entre 58 e $95 \%$ (Tabela 7).

Mais uma vez, os aldeídos orto-substituídos forneceram o produto de homo-aldol em maior diastereosseletividade que o isômero para (entradas 1, 2, 3 e 4). A racionalização para explicar o rendimento não é óbvia, uma vez que os aldeídos ricos em elétrons 57 a e $57 \mathrm{~g}$ apresentaram rendimentos químicos bem distintos, mas excessos diastereo- e enantioméricos comparáveis (entradas 1 e 7).

\section{Reações da 3,4-dibromofuran-2(5H)-ona - acoplamento cruzado mediado por paládio}

A presença de dois brometos vinílicos proporciona à 3,4-dibromofuran-2 $(5 H)$-ona (2) uma posição de destaque na síntese de produtos naturais e não naturais, sendo empregada como substrato para reações de acoplamento cruzado catalisadas por paládio.

O metabólito citotóxico rubrolídeo N (59a), isolado da esponja marinha Sinoicum blochmanni ${ }^{39} \mathrm{o}$ anti-inflamatório inibidor seletivo
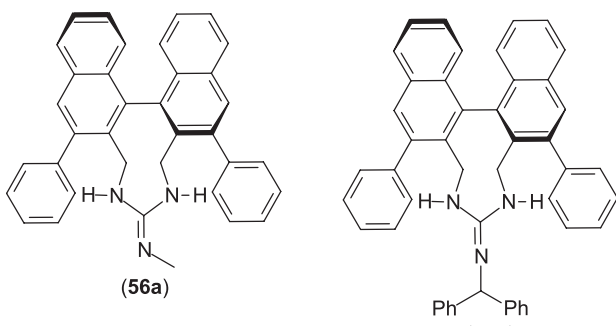

(56b)
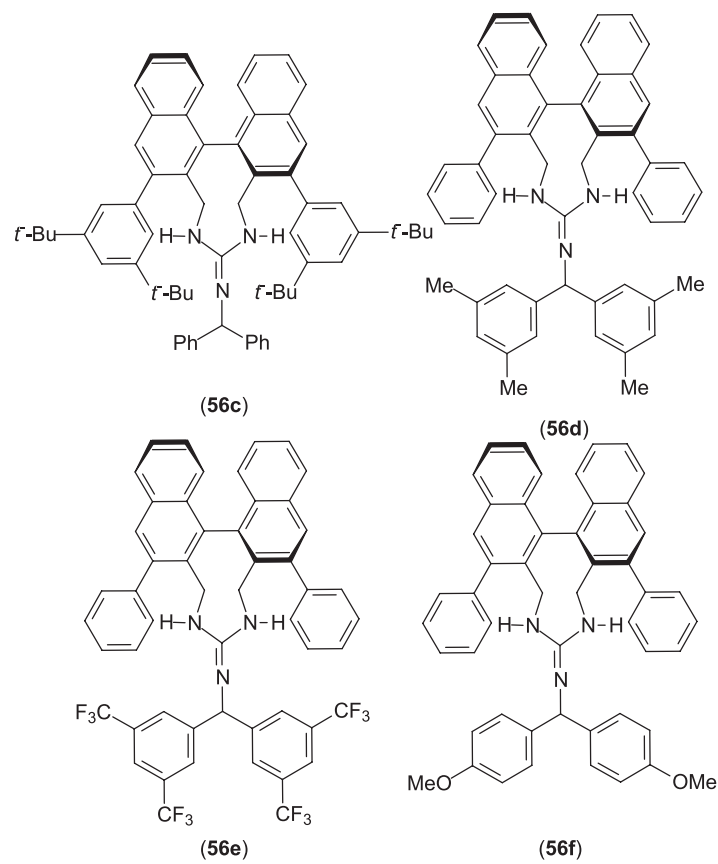

$(56 f)$
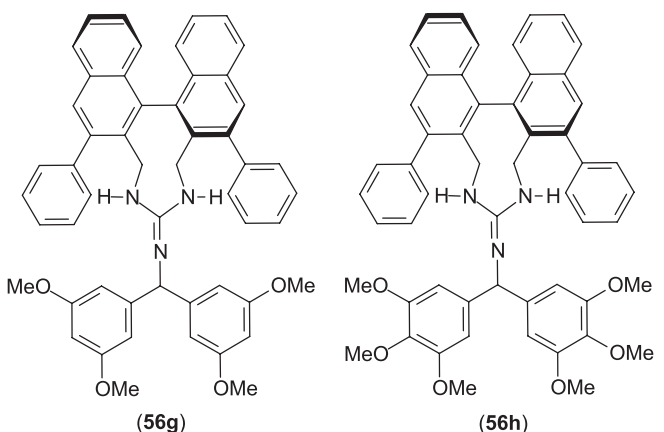

Figura 5. Guanidinas cíclicas quirais organocatalisadores em reações de homo-aldol

Tabela 6. Avaliação do organocatalisador para reação homo-aldólica

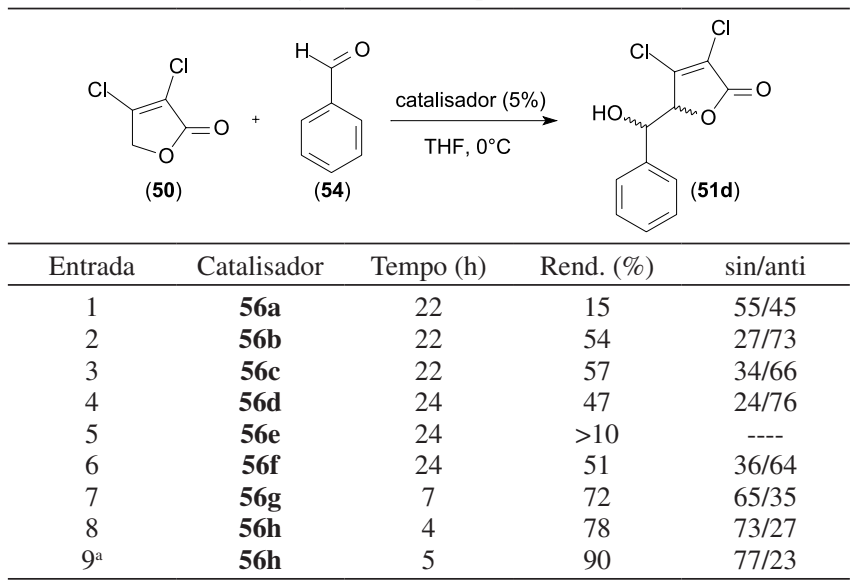

${ }^{\mathrm{a}}$ Reação realizada a $-40{ }^{\circ} \mathrm{C}$ 
Tabela 7. Reação homo-aldol assimétrica entre 2 e aldeídos catalisada por 49h<smiles>O=C1OCC(Br)=C1Br</smiles>

\begin{tabular}{|c|c|c|c|c|}
\hline Entrada & $\mathrm{Ar}-\mathrm{CHO}$ & Produto & $\begin{array}{c}\text { Rend. } \\
(\%)\end{array}$ & e.d $(\%)$ \\
\hline
\end{tabular}

1<smiles>Cc1ccc(C=O)cc1</smiles>

(57a)<smiles>Cc1ccc(C(O)C2OC(=O)C(Br)=C2Br)cc1</smiles>

$95 \quad 72$ 99

(58a)<smiles>O=Cc1ccccc1Br</smiles><smiles>O=C1OC(C(O)c2ccccc2Br)C(Br)=C1Br</smiles>

91 76 96

(57b)

(58b)<smiles>O=Cc1ccc(Br)cc1</smiles>

(57c)<smiles>O=C1OC(C(O)c2ccc(Br)cc2)C(Br)=C1Br</smiles>
87 74 96

(58c)

4<smiles>Cc1ccccc1C=O</smiles>
(57d)<smiles>Cc1ccccc1C(O)C1OC(=O)C(Br)=C1Br</smiles>

(58d)<smiles>O=Cc1ccco1</smiles>
(57e)<smiles>O=C1OC(C(O)c2ccco2)C(Br)=C1Br</smiles>

(58e)<smiles>O=Cc1cccc2ccccc12</smiles>

(57f)<smiles>O=C1OC(C(O)c2cccc3ccccc23)C(Br)=C1Br</smiles>

(58f)<smiles>COc1ccc(C=O)cc1</smiles>

(57g)<smiles>COc1ccc(C(O)C2OC(=O)C(Br)=C2Br)cc1</smiles>

58 da COX-2, Vioxx ${ }^{\circledR}$ (59b), retirado do mercado em $2004 ;{ }^{40}$ e o pigmento fluorescente, aurantricolídeo A (59c), isolado do fungo Tricholoma aurantium, ${ }^{41}$ são exemplos de furanonas substituídas em C3 e C4 que podem ser obtidas por reações de acoplamento a partir de $\mathbf{2}$ (Figura 6).

As duas primeiras metodologias de alquilação por reações de acoplamento de $\mathbf{3}$ foram descritas por Bellina e colaboradores. ${ }^{42,43}$ Nestes trabalhos foi realizada a substituição seletiva dos brometos vinílicos para a formação de 3,4-di-alquil furanonas. A condição descrita pelos autores como ideal para a reação de Suzuki em C4 utiliza $20 \mathrm{~mol} \%$ de $\mathrm{AsPh}_{3}$ e três equivalentes de $\mathrm{Ag}_{2} \mathrm{O}$ como base. O tamanho da cadeia e a presença de heteroátomo nos ácidos alquil borônicos 60a-d não forneceram mudanças significativas no rendimento das reações, que variaram entre 79 e 69\% (Tabela 8). A síntese das furanonas 3,4-dialquil substituídas foi completada através de reação de Stille entre as alquil furanonas $\mathbf{6 1 b - d}$ com três equivalentes de tetrametil estanana (62) na presença de $\mathrm{CuI}$ (Esquema 28).

Tabela 8. Reação de Suzuki de 2 mediada por $\mathrm{Ag}_{2} \mathrm{O}$ e $\mathrm{AsPh}_{3}$

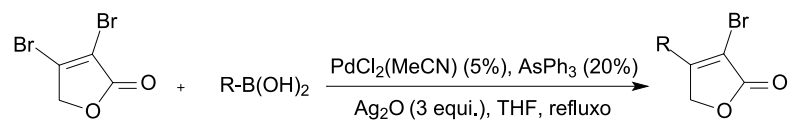

(3)

(60a-d)

(61a-d)

$\begin{array}{llll}\text { Entrada } & \mathrm{R}-\mathrm{B}(\mathrm{OH})_{2} & \text { Produto } & \text { Rend. }(\%)\end{array}$<smiles>CCCCC1=C(Br)C(=O)OC1</smiles>

79

(61a)
2

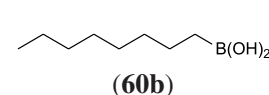

(60b)

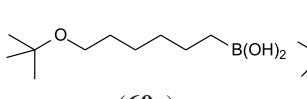

(60c)<smiles>CCCCCCCCC1=C(Br)C(=O)OC1</smiles>

(61b)<smiles>CC(C)(C)OCCCCCCC1=C(Br)C(=O)OC1</smiles>

(61c)

$4>_{\mathrm{B}(\mathrm{OH})_{2}}$

(60d)
69

(61d)

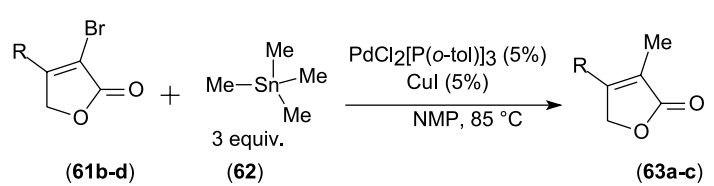<smiles>[R16][R16]([H])([H])[O-]</smiles><smiles>CS(=O)(=O)c1ccc(C2=C(c3ccccc3)C(=O)OC2)cc1</smiles>

Vioxx® (59b)<smiles>O=c1oc2cc3cc(O)c(O)cc3oc-2c1-c1ccccc1</smiles>

Aurantricolídeo A

(59c)

Figura 6. Estruturas do rubrolídeo N, Vioxx ${ }^{\circledR}$ e Aurantricolídeo A
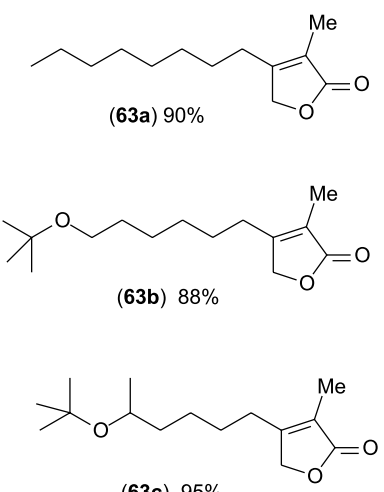

(63c) $95 \%$

Esquema 28. Reação de Stille a partir das furanonas $\mathbf{6 1 b - d}$ 
Rubrolídeos são metabólitos secundários isolados das esponjas Ritterella rubra e Sinoicum blochmanni. ${ }^{39,45}$ Estes produtos naturais, apesar de estruturalmente simples, apresentam diversos tipos de atividade biológica importantes, como inibição da proteína fosfatase, citotoxidade contra células humanas cancerosas, além de atuarem como antibióticos. Durante a síntese do rubrolídeo N (59a), Bellina e colaboradores expandiram, para os ácidos fenil-borônicos, a metodologia desenvolvida para a reação de Suzuki com os ácidos alquil-borônicos. ${ }^{43}$

Além da reação de Suzuki, a síntese das 4-aril furanonas 64a-e foi realizada através da reação de Stille com ariltributil estananas (Figura 7). ${ }^{43}$ Quando o grupamento arila é o mesmo na estanana ou no ácido borônico os rendimentos são equivalentes para as duas metodologias (Tabela 9, comparar entrada 1 com 4 e 2 com 7). Acredita-se que nas reações de Suzuki a função da prata é complexar com o átomo de bromo após a adição oxidativa, facilitando o ataque nucleofílico do grupamento arila ao paládio. Sem a presença do $\mathrm{Ag}_{2} \mathrm{O}$ não é observada a formação do produto de acoplamento, sendo obtida grande quantidade do produto de homo-acoplamento do ácido borônico.<smiles>CC(C)(C)OC(=O)C(Br)=C(c1ccc(Br)c(Cl)c1)C(C)(C)C</smiles><smiles>O=C1OCc2ccccc2C1Br</smiles><smiles></smiles><smiles>COc1ccc(C2=C(Br)C(=O)OC2(C)C(C)(Cl)Cl)cc1Cl</smiles><smiles>CC(C)(C)OC1=C(Br)C(=O)OC1c1ccc(F)cc1</smiles>

Figura 7. Estruturas das aril furanonas 64a-e

Tabela 9. Formação das aril furanonas 57a-d via reação de Suzuki ou Stille

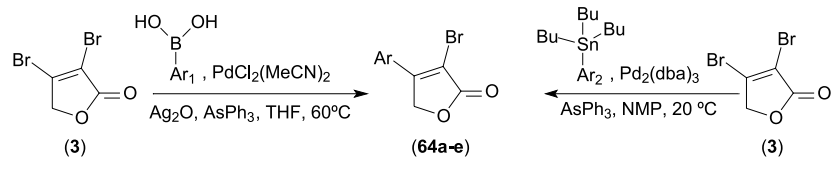

Entrada $\mathrm{Ar}-\mathrm{B}(\mathrm{OH})_{2}$ Rendimento Entrada $\mathrm{Ar}^{-} \mathrm{SnBu}_{3}$ Rendimento

\begin{tabular}{cccccc} 
& & $(\%)$ & & & $(\%)$ \\
\hline 1 & $\mathrm{C}_{6} \mathrm{H}_{5}$ & 66 & 4 & $\mathrm{C}_{6} \mathrm{H}_{5}$ & 59 \\
2 & $3-\mathrm{Cl}$, & 79 & 5 & $4-\mathrm{FC}_{6} \mathrm{H}_{4}$ & 68 \\
& $4-\mathrm{MeOC}_{6} \mathrm{H}_{3}$ & & & & \\
3 & $4-\mathrm{ClC}_{6} \mathrm{H}_{4}$ & 61 & 6 & $4-\mathrm{MeC}_{6} \mathrm{H}_{4}$ & 58 \\
& & & 7 & $\begin{array}{c}3-\mathrm{Cl}_{2}, \\
4-\mathrm{MeOC}_{6} \mathrm{H}_{3}\end{array}$ & 73 \\
\hline
\end{tabular}

De posse das 4-aril furanonas 64a-d a síntese dos análogos de rubrolídeos 65a-e foi realizada em duas etapas, via reação homoaldol mediada por TBDMSOTf com para-anisaldeído ou 3-bromo4-metóxi-benzaldeído, seguido da desidratação do intermediário 66 com dois equivalentes de DBU (Esquema 29). O rubrolídeo N (59a) foi obtido em $47 \%$ de rendimento após desproteção das metoxilas em 65e com 5 equivalentes de $\mathrm{BBr}_{3}$ em DCM (Esquema 30).

Apesar da grande contribuição de Bellina e colaboradores em relação às reações de acoplamento da furanona $\mathbf{2}$, somente em 2002 foi descrita uma metodologia na qual não era necessária a presença de reagentes caros e tóxicos como o $\mathrm{Ag}_{2} \mathrm{O}$ e o $\mathrm{AsPh}_{3}$, respectivamente. Neste trabalho, a furanona 2 foi diarilada com 2,4 equivalentes do ácido fenil-borônico (38) em um sistema bifásico na presença de
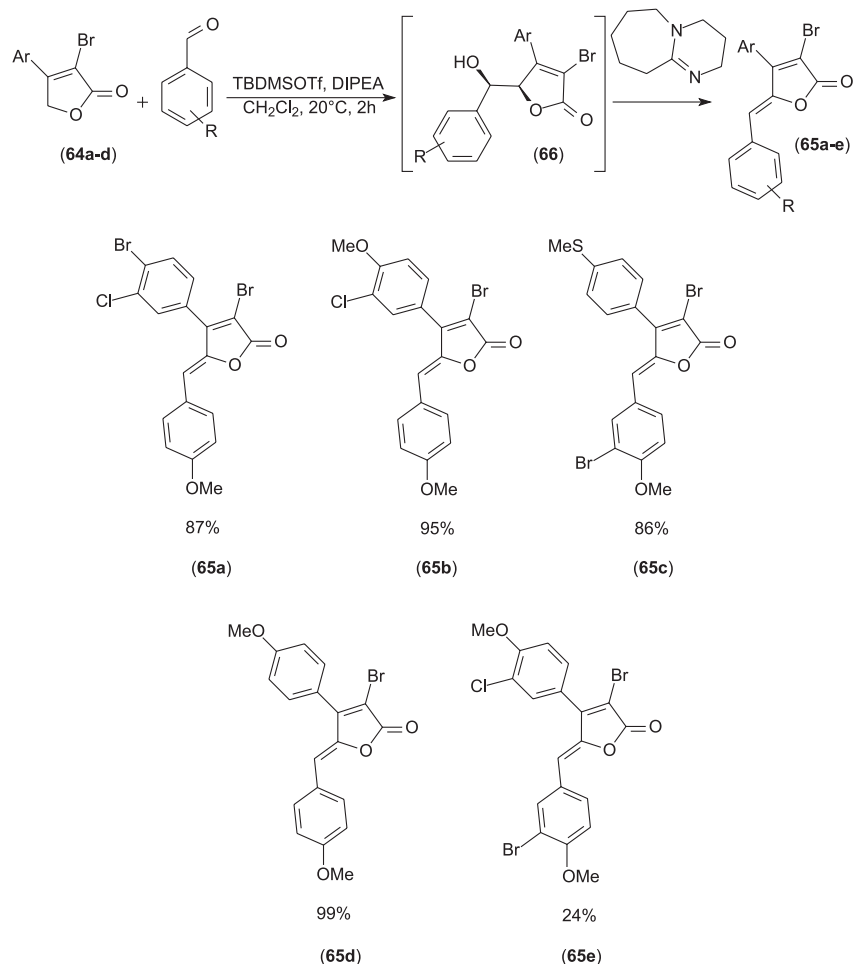

Esquema 29. Síntese de análogos de rubrolídeos

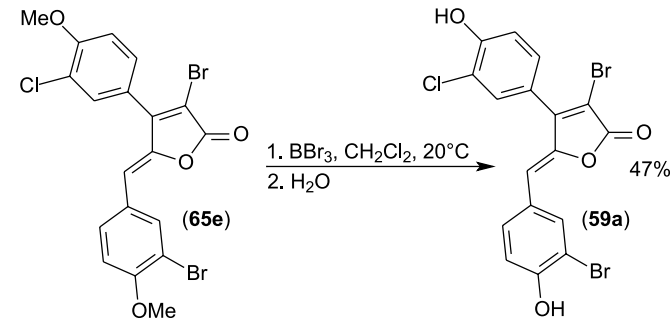

Esquema 30. Síntese do rubrolídeo N (59a)

$\mathrm{PdCl}_{2}\left(\mathrm{PPh}_{3}\right)_{2}$ e CsF, além de um catalisador de transferência de fase (Esquema 31). ${ }^{29}$

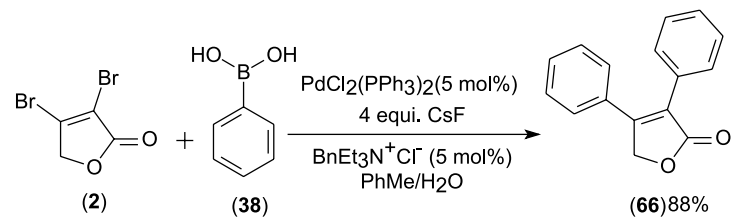

Esquema 31. Reação de Suzuki de 2 em sistema bifásico

A aplicação desta metodologia na síntese do Vioxx (59b) partindo-se de 2 e realizada somente em três etapas demonstra o potencial sintético desta furanona em reações de acoplamento cruzado mediado por paládio (Esquema 32).

Na busca por substâncias com potencial atividade citotóxica, assim como os rubrolídeos, Bellina e colaboradores publicaram a síntese formal do nostoclídeo I e II (5c e 68, respectivamente) (Esquema 33), ${ }^{46}$ e alquinil furanonas (Esquema 34$).{ }^{47}$ Nestas sínteses, a formação das ligações C-C envolve reações de acoplamento. Uma reação de Stille com a vinil estanana (69) seguida de hidrogenação leva à formação de 70 que, após a reação de Negishi com o organozinco 71, forma o intermediário 72, que é o mesmo utilizado por Boukouvalas na síntese total de $\mathbf{5 c}$ e $\mathbf{6 8 a}-\mathbf{b} .{ }^{48} \mathrm{O}$ rendimento de $36 \%$ desta última 


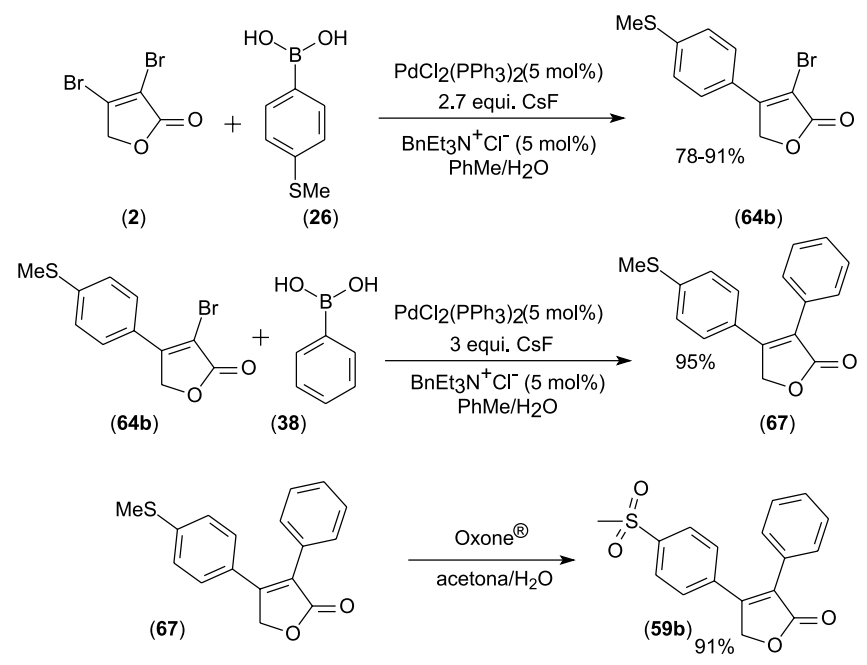

Esquema 32. Síntese do Vioxx ${ }^{\circledR}(59 b)$

etapa ilustra como é sensível a utilização de furanonas enolizáveis em meio básico. Recentemente, empregando uma rota semelhante, Barbosa e colaboradores sintetizaram análogos de nostoclídeos com atividade antimicrobiana. ${ }^{49}$

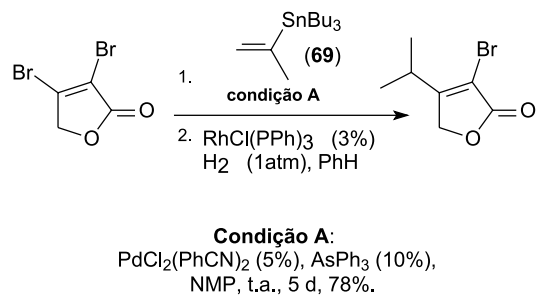

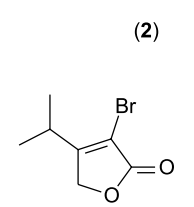

(2)

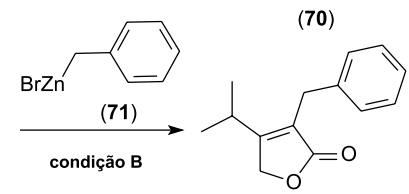

(70)

(72)

Condição B $\mathrm{PdCl}_{2}\left[\mathrm{P}(\mathrm{o} \text {-tol) } 3]_{2}(5 \%)\right.$ DMF/THF $(1: 1), 60^{\circ} \mathrm{C}, 5 \mathrm{~h}, 36 \%$

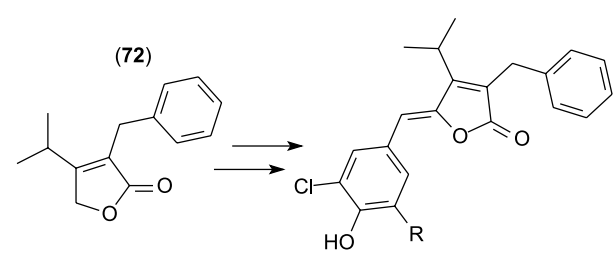

$\mathrm{R}=\mathrm{Cl}$, nostoclídeo $\mathrm{I}(\mathbf{5 c})$ $\mathrm{R}=\mathrm{H}$, nostoclídeo II $(\mathbf{6 8})$

Esquema 33. Síntese formal do nostoclídeo I (5) e II (68)

A formação das alquinil furanonas 73a-d partindo de 2 é o único exemplo descrito para a reação de Sonogashira utilizando este substrato (Esquema 34). ${ }^{47}$ Apesar da alquinilação ter sido realizada com outros alcinos, a avaliação da citotoxidade foi efetuada somente para as moléculas 73a-d. Estas substâncias apresentaram potente atividade citotóxica in vitro contra células cancerosas do pulmão, da mama e do sangue. Estes resultados indicam estas alquinil furanonas como potenciais drogas no tratamento destas neoplasias.

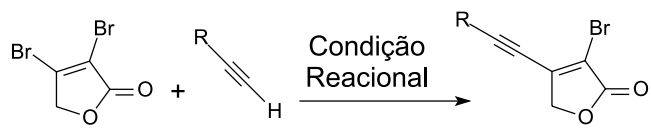

(2)

(73a-d)

Condição Reacional

$\mathrm{PdCl}_{2}(\mathrm{PhCN})_{2}(5 \%)$, Cul (10\%), $\mathrm{P}(2 \text {-furil })_{3}$,

$\mathrm{KF}$ (4equi.), $\mathrm{BnEt}_{3} \mathrm{NCl}, 60^{\circ} \mathrm{C}$.<smiles>CCCCC#CC1=C(Br)C(=O)OC1</smiles><smiles>CC(C)(C)C#CC1=C(Br)C(=O)OC1</smiles>

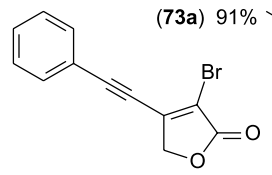

(73c) $85 \%$

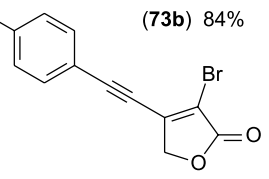

(73d) $71 \%$
Esquema 34. Formação de alquinil furanonas via reação de Sonogashira

Em todas as reações descritas para 2, seu comportamento como nucleófilo é o predominante. O seu potencial como eletrófilo foi investigado recentemente com a reação desta furanona com aminas, sendo obtida uma variedade de $\alpha$-bromo enaminonas em rendimentos entre 23 e $92 \%$. A baixa basicidade da amina é essencial para o sucesso da reação, em função da instabilidade de $\mathbf{2}$ em meio básico. Nesta metodologia torna-se necessária a adição de um equivalente adicional da amina ou de $\mathrm{NaHCO}_{3}$ para neutralizar o $\mathrm{HBr}$ liberado no meio reacional a partir da reação de adição-eliminação. Nas condições estudadas, a única amina alifática que reagiu com 2 foi a morfolina (75) (Tabela 10). Adicionalmente, este mesmo estudo descreveu a formação do alquilideno $\mathbf{7 4} \mathrm{em}$ rendimento modesto. Contudo, cabe destacar que esta foi a primeira participação de $\mathbf{2}$ em uma reação multicomponente descrita na literatura (Esquema 35). ${ }^{50}$

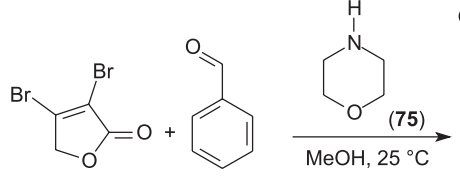

(2)
(54)

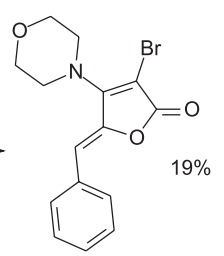

(74)
Esquema 35. Reação multicomponente de 2 com morfolina (75) e benzaldeído (54)

\section{CONSIDERAÇÕES FINAIS}

O estudo da reatividade do ácido mucobrômico (1) e da 3,4-dibromofuran-2(5H)-ona (2) apresentou significativo avanço desde o início do século XXI. No entanto, muitos desafios ainda persistem. Por exemplo, reações de acoplamento cruzado envolvendo $\mathbf{1}$ e $\mathbf{2}$ podem ser estendidas a outros metais além do paládio, enquanto as transformações em meio básico ainda são problemáticas para as duas furanonas. Tão importante quanto estes aspectos é a investigação da capacidade de $\mathbf{2}$ atuar como eletrófilo, pois os registros deste padrão reacional são ainda escassos na literatura.

Finalmente, os butenolídeos $\mathbf{1}$ e $\mathbf{2}$ são sinthons versáteis para a construção de moléculas complexas por serem polifuncionalizados e várias reações quimio-, regio- e estereosseletivas de formação de ligação C-C e C-heteroátomo já foram descritas em bons rendimentos (Esquema 36). 
Tabela 10. Síntese de $\alpha$-bromo enaminonas cíclicas<smiles>C[O+]=C1OCC(Br)=C1Br</smiles>

(3)
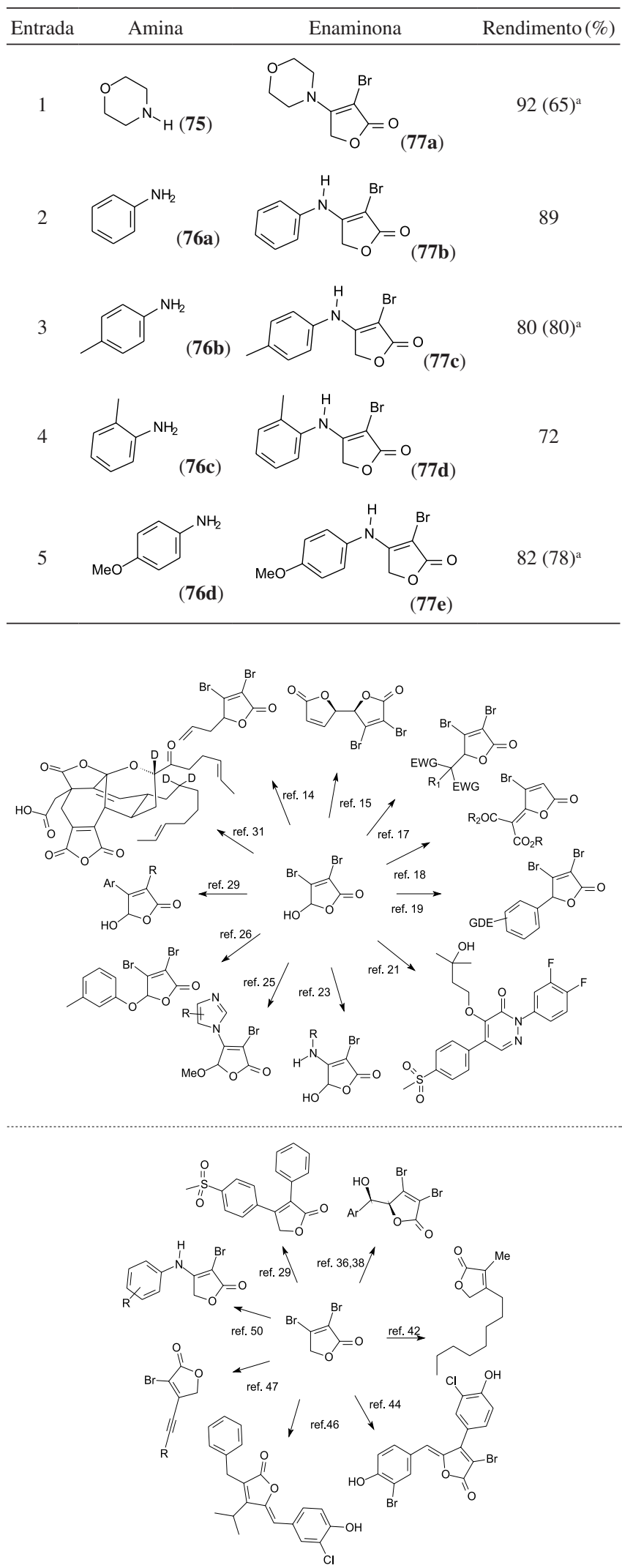

Esquema 36. Resumo das aplicações sintéticas dos butenolídeos 1 e 2
$\mathrm{MeOH}, 25^{\circ} \mathrm{C}$

Entrada Rendimento(\%)

aRendimento quando $\mathrm{NaHCO}_{3}$ foi utilizado como base de sacrifício.

\section{AGRADECIMENTOS}

Ao apoio financeiro do Conselho Nacional de Desenvolvimento Científico e Tecnológico - CNPq, à Coordenação de Aperfeiçoamento de Pessoal de Nível Superior - CAPES e Fundação de Amparo à Pesquisa do Estado da Bahia - FAPESB pelas bolsas de produtividade em pesquisa, mestrado e PIBIC.

\section{REFERÊNCIAS}

1. Hudlický, T.; Reed, J.; The Way of Synthesis, Wiley-VCH: Weinheim, 2007.

2. Corey, E. J.; J. Org. Chem. 2004, 69, 2917.

3. Brocksom, T. J.; Brocksom, U.; Constantino, M. G.; Quim Nova 2008, 31, 937.

4. Sanseverino, A. M.; Quim. Nova 2002, 25, 660; Sanseverino, A. M.; Quim. Nova 2000, 23, 102; Merat, L. M. O. C.; Gil, R. A. S. S.; Quim. Nova 2003, 26, 779 .

5. Galembeck, F.; Barbosa, C. A. S.; Sousa, R. A.; Quim. Nova 2009, 32, 571; Ferreira, V. F.; Rocha, D. R.; Silva, F. C.; Quim. Nova 2009, 32, 623; Mota, C. J. A.; Silva, C. X. A.; Gonçalves, V. L. C.; Quim. Nova 2009, 32, 639.

6. Carlson, R.; Carlson, J.; Desing and Optimization in Organic Synthesis, $2^{\text {nd }}$ ed., Elsevier: Amsterdam, 1992.

7. Wender, P. A.; Verma, V. A.; Paxton, T. J.; Pillow, T. H.; Acc. Chem. Res. 2008, 41, 40.

8. Lenardão, E. J.; Freitag, R. A.; Dabdoub, M. J.; Batista, A. C. F.; Silveira, C. C.; Quim. Nova 2003, 26, 123.

9. Barbosa, L. C. A.; Teixeira, R. R.; Pinheiro, P. F.; Maltha, C. R. A.; Demuner, A. J.; Quim. Nova 2010, 33, 1163.

10. Taylor, G. A.; Org. Sinth.1963, 4, 688.

11. Bellina, F.; Rossi, R.; Synthesis 2007, 12, 1887.

12. Kar, A.; Gogoi, S.; Argade, N. P.; Tetrahedron 2005, 61, 5297.

13. Moore, R. D.; Katon, J.; Appl. Spectrosc. 1978, 32, 145. 
14. Zhang, J.; Blazecka, P. G.; Berven, H.; Belmont, D.; Tetrahedron Lett. 2003, 44, 5579.

15. Angell, P.; Zhang, J.; Belmont, D. T.; Davidson, J. G.; Tetrahedron Lett. 2005, 46, 2029.

16. Kurti, L.; Czako, B.; Strategic Applications of Named Reactions in Organic Synthesis, Elsevier: Amsterdam, 2005.

17. Zhang, J.; Sarma, K. D.; Curran, T. T.; Belmont, D. T.; Davidson, J. G.; J. Org. Chem. 2005, 70, 5890.

18. Zhang, J.; Sarma, K. D.; Curran, T. T.; Tetrahedron Lett. 2005, 46, 6433.

19. Zhang, J.; Curran, T. T.; Blazecka, P. G.; Tetrahedron Lett. 2007, 48, 2611.

20. Sulikowski, G. A.; Liu, W.; Agnelli, F.; Corbett, R. M.; Luo, Z.; Hershberger, S. J.; Org. Lett. 2002, 4, 1451.

21. Kerdesky, F. A. J.; Leanna, M. R.; Zhang, J.; Li, W.; Lallaman, J. E.; Ji, J.; Morton, H. E.; Org. Process Res. Dev. 2006, 10, 512.

22. Ritter, J. M.; Rang, H. P.; Dale, M. M.; Flower, R. J.; Farmacologia, $5^{\text {a }}$ ed., Elsevier: Rio de Janeiro, 2004.

23. Lattmann, E.; Sattayasai, N.; Niamsanit, S.; Dunn, S.; Bioorg. Med. Chem. Lett. 2005, 15, 919.

24. Edafiogho, I. O.; Phillips, O. A.; Udo, E. E.; Samuel, S.; Beigy, R.; Eur. J. Med. Chem. 2009, 44, 967.

25. Lattmann, E.; Sattayasai, N.; Schwalbe, C. S.; Niamsanit, S.; Billington, D. C.; Lattmann, P.; Langley, C. A.; Singh, H.; Dunn, S.; Curr. Drug. Disc. Technology 2006, 3, 125.

26. Zhang, J.; Curran, T. T: Belmont, D.; Blazecka, P. G.; Pflum, D.; Org. Lett. 2003, 5, 5015.

27. Tsuji, J. Em Palladium in organic synthesis; Tsuji, J., ed.; SpringerVerlag: Berlin, 2005.

28. Hartwig, J.; Organotransition metal chemistry: from bonding to catalysis, University Science Books: Sausalito, 2009.

29. Zhang, J.; Blazecka, P. G.; Belmont, D.; Davidson, J. G.; Org. Lett. 2002, 4, 4559.

30. Shorunov, S. V.; Stoyanovich, F. M.; Krayushkin, M. M.; Russ. Chem. Bull. Int. Ed. 2004, 53, 2238.

31. Sulikowski, G. A.; Agnelli, F.; Spencer, P.; Koomen, J. M.; Russell, D. H.; Org. Lett. 2002, 4, 1447.
32. Gomez-Paloma, L.; Aquino, M.; Bruno, I.; Org. Lett. 2006, 8, 4831.

33. Gomez-Paloma, L.; Guerrero, M. D.; Aquino, M.; Bruno, I.; Terencio, M. C.; Paya, M.; Riccio, R.; J. Med. Chem. 2007, 50, 2176.

34. Beletskaya, I. P.; Cheprakov, A. V.; Chem. Rev. 2000, 100, 3009; Dounay, A. B.; Overman, L. E.; Chem. Rev. 2003, 103, 2945.

35. Shibasaki, M.; Vogel, E. M.; J. Organomet. Chem. 1999, 576, 1; Smith, C. R.; Rajanbabu, T. V.; Tetrahedron 2010, 66, 1102.

36. Das Sarma, K.; Zhang, J.; Curran, T. T.; J. Org. Chem. 2007, 72, 3311.

37. Carey, F. A.; Sundberg, R. J.; Advanced Organic Chemistry, $4^{\text {th }}$ ed., Springer: New York, 2007, p. 359.

38. Ube, H.; Shimada, N.; Terada, M.; Angew. Chem., Int. Ed. 2010, 49, 1858. Para outra descrição recente de reação homo-aldol assimétrica mediada por organocatalisador bifuncional, ver: Luo, J.; Wang, H.; Han, X.; Xu, L.-W.; Kwiatkowski, J.; Huang, K.-W.; Lu; Y.; Angew. Chem., Int. Ed. 2011, 50, 1861.

39. Ortega, M. J.; Zubía, E.; Ocaña, J. M.; Naranjo, S.; Salvá, J.; Tetrahedron 2000, 56, 3963.

40. http://www.anvisa.gov.br, acessada em Maio 2011.

41. Klostermeyer, D.; Knops, L.; Sindlinger, T.; Polborn, K.; Steglich, W.; Eur. J. Org. Chem. 2000, 4, 603.

42. Bellina, F.; Rossi, R.; Anselmi, C.; Tetrahedron Lett. 2001, 42, 3851.

43. Bellina, F.; Rossi, R.; Raugei, E.; Synlett 2000, 12, 1749.

44. Bellina, F.; Rossi, R.; Anselmi, C.; Viel, S.; Mannina, L.; Tetrahedron 2001, 57, 9997.

45. Pearce, A. N.; Chia, E. W.; Berridge, M. V.; Maas, E. W.; Page, M. J.; Webb, V. L.; Harper, J. L.; Copp, B. R.; J. Nat. Prod. 2007, 70, 111.

46. Bellina, F.; Rossi, R.; Synthesis 2002, 18, 2729.

47. Bellina, F.; Rossi, R.; Falchi, E.; Tetrahedron 2003, 59, 9091.

48. Boukouvalas, J.; Maltais, F.; Lachance, N.; Tetrahedron Lett. 1994, 35, 7897.

49. Barbosa, L. C. A.; Maltha; C. R. A.; Demuner, A. J.; Pinheiro, P. F.; Varejão, J. O. S.; Montanari, R. M.; Andrade, N. J.; Quim. Nova 2010, 33, 2020.

50. Cunha, S.; Oliveira, C. C.; Sabino, J. R.; J. Braz. Chem. Soc. 2011, 22 , 598. 